\title{
Introduction to the $25^{\text {th }}$ Anniversary Issue of Online Learning
}

\author{
Peter Shea \\ Editor-in-Chief, Online Learning \\ The University at Albany, SUNY
}

This issue marks the 25th volume of the Online Learning Consortium's open access, peerreviewed scholarly journal, Online Learning (OLJ). The journal has been published continuously since 1997, first as the Journal of Asynchronous Learning Networks (JALN) before merging with the Journal of Online Learning and Teaching (JOLT) and changing names to the simpler Online Learning. This is noteworthy for a few reasons. Publishing on this topic for 25 years makes OLJ among the first scholarly publication dedicated to the topic of online education. The journal has also been open access since before open access was an organizing concept.

The journal grew out of a recognition that we needed systematic evidence of the feasibility of offering distance education through online instruction. The organization supporting the journal in the early years was the Alfred P. Sloan Foundation, which also sponsored a major grant program that allowed the Online Learning Consortium (then Sloan-C) and many institutions to get started in online education. The use of computer networks in education combined with browser based interfaces were still a novelty in the 1990s. Did a more ubiquitous and user-friendly internet change the rules for offering distance education? The Sloan Foundation's Frank Mayadas suggested that it did in one of the first papers published in the journal.

There were also concerns about the efficacy and acceptability of online instruction. These linger today despite voluminous evidence that online instruction can be as good as or better than classroom instruction. This early rationale motivated the publication of initial studies on student and faculty satisfaction with online learning as well as organizational issues related to launching online courses and degree programs. As time went by this work became more sophisticated. Gradually the journal gained prominence and attracted international researchers in the world of online learning such as Terry Anderson and Randy Garrison who published pioneering work on their conceptual model for online learning, the Community of Inquiry framework.

As the journal grew it became apparent that it could not be published on a simple website and needed a purpose-built platform. In keeping with JALN and OLJ's roots as free and open educational resources, the organization decided to move to the Open Journal System (OJS) in 2007. Transferring two decades of issues was slowly completed and the journal has had one consolidated home on OJS ever since.

In 2014 OLC began an ongoing effort to improve the standing of the journal in the world of scholarly publication. This included adding new members to our then core editorial team of Karen Swan, Tony Picciano and Katrina Meyer. Early new recruits to OLJ included Charles Graham, Shanna Smith Jaggars, and Jennifer Richardson. Our editorial team continues to grow 
and improvements have led to OLJ being ranked as the top journal in online learning by Google Scholar metrics. True to our open access foundations, we also now rank in the top 5\% of all open access journals in the broader field of education.

The world has changed dramatically since the early days of online learning. Even before the pandemic, millions of students were enrolled in online courses and programs. Thousands of studies have investigated online education and numerous journals now provide an outlet for this line of research. Our 25th Anniversary issue reflects some of the most recent changes facing online learning and the broader education sector. This full special issue, edited by Shanna Smith Jaggers of Ohio State University, focuses on online education in the age of the pandemic with, as she writes, insights on how to better prepare for future public emergencies, as well as how to improve student success more generally in both online and in-person settings. We owe Dr. Jaggers an enormous debt of gratitude for managing the hundreds of submissions we received (in addition to her day job and during a pandemic) and expertly curating the articles in this very special issue.

Please join us in celebrating our first 25 years of online learning research with OLJ! 